\title{
Initial clinical presentation and spectrum of pheochromocytoma: a study of 94 cases from a single center
}

\author{
Henrik Falhammar ${ }^{1,2}$, Magnus Kjellman ${ }^{2,3}$ and Jan Calissendorff ${ }^{1,2}$ \\ ${ }^{1}$ Department of Endocrinology, Metabolism and Diabetes, Karolinska University Hospital, Stockholm, Sweden \\ ${ }^{2}$ Department of Molecular Medicine and Surgery, Karolinska Institutet, Stockholm, Sweden \\ ${ }^{3}$ Department of Breast and Endocrine Surgery, Karolinska University Hospital, Stockholm, Sweden \\ Correspondence should be addressed to J Calissendorff: jan.calissendorff@sll.se
}

\begin{abstract}
Background: With the increasing access to imaging more pheochromocytomas are diagnosed in the workup of adrenal incidentalomas. This may have changed the occurrence of the classic presentation with hypertension and the classic triad (headaches, sweating and palpitation).

Methods: We reviewed 94 consecutive cases of pheochromocytomas. Two cases of ectopic ACTH-syndrome were subsequently excluded.

Results: Of the 92 cases included $64 \%$ had presented as an incidentaloma, $32 \%$ as a suspected pheochromocytoma and $4 \%$ had been screened because of previously diagnosed MEN2A. Those screened were youngest while those with incidentalomas were oldest. The females were more common in the incidentaloma and the screening groups, and males in the suspected pheochromocytoma group. Measurements of noradrenaline/ normetanephrine levels were highest in the suspected pheocromocytoma group and lowest in the screening group. Hypertension was present in $63 \%$ of the incidentalomas, $79 \%$ of suspected pheochromocytomas and in none of the screening group. Paroxysmal symptoms were present in almost all with suspected pheochromocytoma while only in half of the other groups. The suspected pheocromocytoma group had most symptoms and the screening group least. The classic triad was present in $14 \%$ of the incidentalomas, in $28 \%$ of the suspected and in none of the screening group, while no symptoms at all was present in $12 \%, 0 \%$ and $25 \%$, respectively. Pheochromocytoma crisis occurred in $5 \%$. There was a positive correlation between tumor size vs hormone levels, and catecholamine levels vs blood pressure.

Conclusion: Clinicians need to be aware of the modern presentation of pheochromocytomas since early identification can be life-saving.
\end{abstract}

\author{
Key Words \\ - pheochromocytoma \\ - symptoms \\ - adrenal incidentaloma \\ - blood pressure \\ - cardiovascular disease \\ - diabetes
}

Endocrine Connections (2018) 7, 186-192

\section{Introduction}

Pheochromocytomas are neuroendocrine tumors arising from chromaffin cells of the adrenal medulla or in extraadrenal paraganglia producing catecholamines. Tumors outside the adrenals are usually called extra-adrenal pheochromocytomas or paragangliomas and only represent around 15-20\% of all catecholamine-secreting tumors (1). Pheochromocytomas are rare but in certain groups such as in patients with adrenal incidentalomas $0.6-4.2 \%$ are affected $(2,3,4)$. Pheochromocytoma is a serious condition which can be fatal if not diagnosed
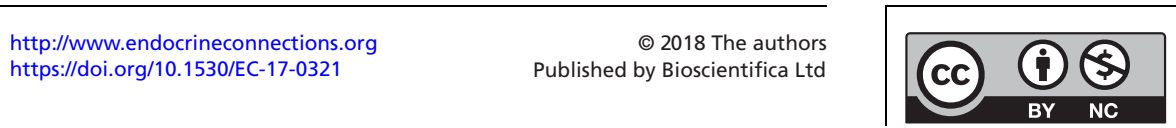

This work is licensed under a Creative Commons Attribution-NonCommercial 4.0 International License. 
and/or managed appropriately $(1,5)$. It has been estimated that at least $25 \%$ of all affected by pheochromocytomas were never diagnosed during life (6).

The presenting symptoms of pheochromocytomas can vary to a large extent and similar symptoms can occur in many other clinical conditions. Thus, it is often called the great mimic and there can be a significant delay of diagnosis (7). Most cases have previously been found due to symptoms suspected to be related to catecholamine excess, typically paroxysmal hypertension and the classic triad of headaches, sweating and palpitation. However, with the increasing use of high resolution imaging techniques in the past decades more incidentalomas have been detected. It has also been reported that more of all pheochromocytomas were discovered in the workup for incidentalomas (7), but this study only included patients up to 2003. It can be assumed that this development has continued during the last 15 years. Moreover, individuals are also nowadays found in the family screening for genetic syndromes that are associated with catecholamine producing tumors (e.g. multiple endocrine neoplasia type 2, Von Hippel Lindau syndrome, neurofibromatosis type 1 , and mutations in succinate dehydrogenase B, C and D). Thus, the clinical presentation has most likely changed over time and may not be as perceived previously.

The aims of the present study were to determine in a large modern cohort of pheochromocytomas the presenting characteristics and investigate differences in presentation in those presenting as incidentalomas, those with symptoms suspected to be pheochromocytoma and those found in the screening since they had been diagnosed with a familial syndrome.

\section{Subjects and methods}

This retrospective study was conducted at the Department of Endocrinology, Metabolism and Diabetes, Karolinska University Hospital, Stockholm, Sweden. All consecutive patients with an International Classification of Diseases version 10 (ICD-10) code of E27.5 (adrenomedullary hyperfunction) and/or C74.1 (malignant neoplasm of medulla of adrenal gland) and had been admitted and/ or attended the out-patient clinic between June 2005 and June 2016 were eligible for inclusion. The patients' electronic medical files were reviewed manually and those were a pheochromocytoma could not be confirmed were subsequently excluded. The National Population Register was also consulted to find out if the patient was still alive and the date of death was retrieved if applicable

$$
\begin{array}{lr}
\text { http://www.endocrineconnections.org } & \text { ( } 2018 \text { The authors } \\
\text { https://doi.org/10.1530/EC-17-0321 } & \text { Published by Bioscientifica Ltd }
\end{array}
$$

(8). In Sweden, all hospital admissions and specialist out-patient visits are coded with ICD-10 codes by the attending physician and stored in local and national databases (9). Presenting symptoms, co-morbidities, blood pressure, biochemistry, imaging and tumor size recorded in the files were noted. Patients with relapse of their pheochromocytoma were included only for the first episode.

High-performance liquid chromatography (HPLC) was used for determinations of $24 \mathrm{~h}$ urinary adrenaline and noradrenaline (normal $<80$ and $<400 \mathrm{nmol} / 24 \mathrm{~h}$, respectively), and liquid chromatography-tandem mass spectrometry (LC/MS/MS) for plasma metanephrine and normetanephrine (normal $<0.3$ and $<0.6 \mathrm{nmol} / \mathrm{L}$, respectively). Plasma chromogranin A was measured using enzyme-linked immunosorbent assay (ELISA) (normal $<3.0 \mathrm{nmol} / \mathrm{L}$ ).

The Regional Ethical Review Board in Stockholm, Sweden, approved the study. For this type of retrospective study formal consent was not required.

\section{Statistical analysis}

Mean \pm s.D. or median and range were used whichever were appropriate. Continuous variables were between two groups compared with unpaired $t$-test when values (normally distributed) or Mann-Whitney rank-sum test, and between three groups with one-way ANOVA (normal distributions) with post hoc Holm-Sidak test or with ANOVA on ranks test and post hoc Dunn's test. In frequency table calculations, chi-square or Fisher's exact test was used whichever was appropriate. All proportions were calculated discounting missing values. Correlations between variables were assessed using linear regression analysis. Statistical significance was set at $P<0.05$. SigmaStat 3.0 for Windows (Systat Software, San Jose, California) was used for all analysis.

\section{Results}

In total, 94 cases of pheochromocytomas were identified. However, two cases (one with adrenal medullary hyperplasia) had also given rise to an ectopic ACTH syndrome and were subsequently excluded from further analysis since they represent a somewhat different entity, and they have been described in detail previously (10). We were also aware of two adrenocortical cancers with concomitant catecholamine excess, but they had not been given an eligible ICD code (E27.5 or C74.1), and

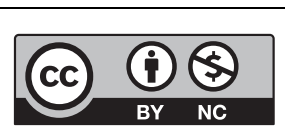

This work is licensed under a Creative Commons Attribution-NonCommercial 4.0 International License. 
their presentations were of an ACC (11), so they were not included either. Thus, 92 cases were included in the analysis of which 59 (64\%) presented as an incidentaloma and 29 (32\%) as a suspected pheochromocytoma, while $4(4 \%)$ were found in the regular catecholamine screening performed due to a previously diagnosed familial syndrome. All patients except three (3\%, all in the incidentaloma group) had adrenalectomy and the diagnosis was confirmed histologically. Of these three individuals, one declined surgery due to old age, one due to extensive separate adenocarcinoma and one deceased prior to surgery due to severe heart failure and severe amyloidosis due to multiple myeloma; the biochemistry results and imaging clearly indicated pheochromocytoma in all, and the response to alfa blockage was excellent. A CT scan had been done in 91 cases (99\%), one had only a MRI. In all 14 had been investigated with MRI (incidentaloma group $n=8$ and suspected pheochromocytoma $n=6$, all showing typical features). In addition, ${ }^{123}$ I-metaiodobenzylguanidine (MIBG) scans had been done in 32 patients (incidentaloma group $n=19$, suspected pheochromocytoma group $n=11$ and screening group $n=2$, respectively) with 28 (88\%) showing a clear uptake in the tumor (incidentaloma group $n=17$ (89\%), suspected pheochromocytoma group $n=10$ (91\%) and screening group $n=1(50 \%)$, respectively, $P=0.252)$. PET was done in four patients (incidentaloma group $n=3$ and screening group $n=1$ ) of which three were with ${ }^{11} \mathrm{C}$-hydroxyephedrine and one with ${ }^{18} \mathrm{~F}$-fludeoxyglucose (incidentaloma), all showing an uptake in the pheochromocytoma. Four patients with incidentaloma (7\%, follow-up time $7.5 \pm 3.9$ years) died compared to five patients with suspected pheochromocytoma $(17 \%$, $11.7 \pm 8.7$ years $)$ and none of the patients screened $(0 \%$, $7.5 \pm 3.9$ years $)(P=0.239)$.

\section{All included patients with a pheochromocytoma}

The mean age at diagnosis was $56.3 \pm 16.1$ years (range 19-85), and the tumor size was $49 \pm 26.7 \mathrm{~mm}$ (range 8-125) (Table 1). The urine adrenaline and/or plasma metanephrine were almost three times the upper level

Table 1 Presenting characteristics of adult patients with pheochromocytomas, also divided into how they presented.

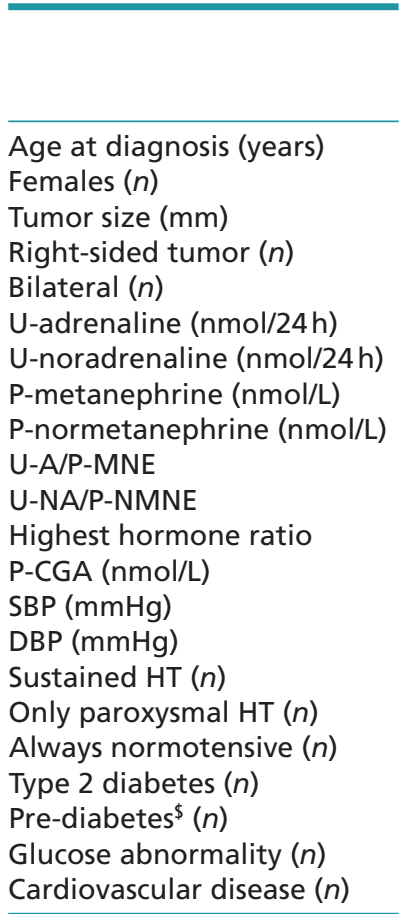

\begin{tabular}{|c|c|}
\hline All $(n=92)$ & $\begin{array}{c}\text { Incidentaloma } \\
\text { presentation }(n=59)\end{array}$ \\
\hline $56.3 \pm 16.1$ & $59.7 \pm 14.1$ \\
\hline $47(51 \%)$ & $35(59 \%)$ \\
\hline $49.0 \pm 26.7$ & $49.2 \pm 24.1$ \\
\hline $50(54 \%)$ & $32(54 \%)$ \\
\hline $1(1 \%)$ & $0(0 \%)$ \\
\hline $119(10-8000)$ & $87(10-8000)$ \\
\hline $858(161-34300)$ & 717 (161-10700) \\
\hline $0.8(0.2-190)$ & $0.8(0.2-12)$ \\
\hline $5.2(0.7-160)$ & $5.0(0.7-61)$ \\
\hline $2.7(0.3-633)$ & $2.3(0.3-100)$ \\
\hline $6.0(0.2-267)$ & $7.3(0.8-102)$ \\
\hline $11.0(1.2-633)$ & $11.0(1.2-102)$ \\
\hline $10.5(2.4-367)$ & $11.0(2.4-170)$ \\
\hline $155 \pm 30$ & $151 \pm 25$ \\
\hline $88 \pm 14$ & $87 \pm 12$ \\
\hline $60(67 \%)$ & $37(63 \%)$ \\
\hline $7(8 \%)$ & $3(5 \%)$ \\
\hline $25(27 \%)$ & $19(32 \%)$ \\
\hline $25(27 \%)$ & $13(22 \%)$ \\
\hline $16(17 \%)$ & $13(22 \%)$ \\
\hline $41(45 \%)$ & $26(44 \%)$ \\
\hline $33(36 \%)$ & $20(34 \%)$ \\
\hline
\end{tabular}

\begin{tabular}{c} 
Pheo suspicion \\
$(n=29)$ \\
\hline $52.4 \pm 17.6$ \\
$9(31 \%)$ \\
$51.8 \pm 32.2$ \\
$16(55 \%)$ \\
$1(3 \%)$ \\
$140(56-584)$ \\
$1500(446-8158)$ \\
$2.0(0.3-7.4)$ \\
$15.5(2.0-47.0)$ \\
$3.6(0.3-633)$ \\
$7.3(0.7-267)$ \\
$16.3(1.3-633)$ \\
$8.9(4.5-367)$ \\
$167 \pm 37$ \\
$92 \pm 18$ \\
$23(79 \%)$ \\
$4(14 \%)$ \\
$2(7 \%)$ \\
$12(41 \%)$ \\
$2(7 \%)$ \\
$14(48 \%)$ \\
$13(45 \%)$ \\
\hline
\end{tabular}

$\begin{array}{r}\hline \\ \hline \boldsymbol{P} \text { value } \\ \hline 0.037 \\ 0.023 \\ 0.675 \\ 0.885 \\ 0.330 \\ 0.321 \\ 0.003 \\ 0.051 \\ <0.001 \\ 0.451 \\ 0.007 \\ 0.014 \\ 0.918 \\ 0.021 \\ 0.135 \\ 0.147 \\ 0.212 \\ 0.008 \\ 0.079 \\ 0.129 \\ 0.821 \\ 0.355 \\ \hline\end{array}$

\begin{tabular}{|c|c|}
\hline Screening $(n=4)$ & $\begin{array}{c}P \text { value } \\
\text { between all } \\
\text { three groups }\end{array}$ \\
\hline $33.3 \pm 8.7$ & 0.001 * \\
\hline $3(75 \%)$ & 0.028 \\
\hline $26.3 \pm 12.5$ & 0.141 \\
\hline $2(50 \%)$ & 0.981 \\
\hline $0(0 \%)$ & 0.333 \\
\hline 225 (159-291) & 0.452 \\
\hline $536(247-825)$ & 0.010 ** \\
\hline $0.8(0.7-1.4)$ & 0.130 \\
\hline $0.9(0.7-1.3)$ & $0.011 *$ \\
\hline $3.2(2.3-4.7)$ & 0.721 \\
\hline $1.8(0.2-2.2)$ & $0.030 * *$ \\
\hline $3.2(3.2-4.7)$ & $0.025 *$ \\
\hline $3.3(2.4-4.2)$ & 0.100 \\
\hline $126 \pm 15$ & 0.010 * \\
\hline $75 \pm 7$ & 0.051 \\
\hline $0(0 \%)$ & 0.006 \\
\hline $0(0 \%)$ & 0.295 \\
\hline $4(100 \%)$ & $<0.001$ \\
\hline $0(0 \%)$ & 0.073 \\
\hline $1(25 \%)$ & 0.195 \\
\hline $1(25 \%)$ & 0.675 \\
\hline $0(0 \%)$ & 0.187 \\
\hline
\end{tabular}

Pheo, pheochromocytoma. All patients screened due to familial syndrome had a previously known RET mutation (MEN2A). U, urinary; $\mathrm{P}$, plasma. U-A/P-MNE, highest U-adrenaline or P-metanephrine level divided the upper level of normal. U-NA/P-NMNE, highest U-noradrenaline or P-normetanephrine level divided the upper level of normal. P-CGA, P-chromogranin A. Reference ranges were for urinary adrenaline and noradrenaline $<80$ and $<400 \mathrm{nmol} / 24 \mathrm{~h}$, respectively, for plasma metanephrine and normetanephrine $<0.3$ and $<0.6 \mathrm{nmol} / \mathrm{L}$, respectively, and for plasma chromogranin A normal $<3.0 \mathrm{nmol} / \mathrm{L}$. SBP, systolic blood pressure. DBP, diastolic blood pressure. Blood pressure before specific treatment for pheochromocytoma such as alfa-blocker. HT, hypertension. $P$ value between the different presentation groups. Bold, $P<0.05$. $P$ value after post hoc Holm-Sidak or Dunn's test: *Significant between all 3 groups; **Significant between incidentaloma presentation and Pheo suspicion groups. \$Defined as fasting plasma glucose 6-6.9 $\mathrm{mmol} / \mathrm{L}$ and/or a $2 \mathrm{~h}$ OGTT value $7.8-11$ and/or a $\mathrm{HbA} 1 \mathrm{c} 42-47 \mathrm{mmol} / \mathrm{mol}$.

http://www.endocrineconnections.org https://doi.org/10.1530/EC-17-0321 (c) 2018 The authors Published by Bioscientifica Ltd

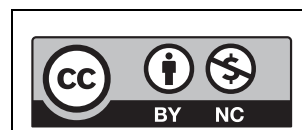

This work is licensed under a Creative Commons Attribution-NonCommercial 4.0 International License. 
of normal, the urine noradrenaline and/or plasma normetanephrine were six times the upper level of normal and if only the highest level was accounted for in each case, the level was 11 times the upper level of normal. Plasma chromogranin A was also elevated. On average, the blood pressure was moderately elevated and two thirds had hypertension. Almost half had some glucose abnormality and a third cardiovascular disease. Paroxysmal symptoms were present in $62 \%$ (Table 2). The most common symptoms with more than a third affected were in falling order: palpitations, anxiety, sweating and headaches. The median number of different symptoms was three and almost a tenth was asymptomatic. The classic triad with headaches, sweating and palpitation was only present in $17 \%$. Five patients (5\%), mean age $51.5 \pm 23.5$ years (range 27-76 years), were diagnosed in conjunction with a pheochromocytoma crisis with multi-organ failure triggered by surgery $(n=2$, coronary bypass and uvulopalatopharyngoplasty, respectively), vaginal delivery $(n=1)$, influenza $(n=1)$ and unknown cause $(n=1)$. None had metastatic disease at presentation; however, two later developed metastasis (both in the suspected pheochromocytoma group).

\section{Presentation as an adrenal incidentaloma, suspected pheochromocytoma or screening}

The majority ( $n=59,64 \%)$ had been found in the workup of an incidentaloma (all had had a CT scan), i.e., there had not been any suspicions of a pheochromocytoma before imaging. The reasons for imaging were abdominal pain/discomfort $(n=36,61 \%)$, hematuria/urine tract issues $(n=10,17 \%)$, thoracic pain/investigation $(n=12$, $20 \%)$ and multi-trauma $(n=1,2 \%)$. In about a third $(n=29$, $32 \%)$, the pheochromocytoma had been suspected and investigations to confirm or rule it out had been ordered. In a small group $(n=4,4 \%)$, biochemical screening for pheocromocytoma had been performed at regular intervals due to familial syndrome with an increased risk of developing a pheochromocytoma. In the incidentaloma group, only in 11 (19\%), a gene test result was found (27\% positive, $n=3$ ) and in suspected pheochromocytoma group, six (21\%) (17\% positive, $n=1)$ but all screened patients had known RET-mutation confirming MEN2A (100\% positive, $n=4)$. When the three groups were compared some differences were found. Those screened were the youngest while those with incidentalomas were the oldest (Table 1). The predominant gender was females in the incidentaloma and the screening groups and males in the suspected pheochromocytoma group. Measurements of noradrenaline/normetanephrine levels were highest in the suspected pheocromocytoma group and lowest in the screening group. There were no differences in adrenaline/metanephrine levels between the groups. The highest hormone ratio was in the suspected and lowest in the screening group. Systolic blood pressure was highest in the suspected group and lowest in the screening group. Constant hypertension was present in $63 \%$ in the incidentaloma, $79 \%$ in the suspected pheochromocytoma but in none of the screening group, while only paroxysmal hypertension was present in 5\%, $14 \%$ and $0 \%$, respectively. There was a tendency to be

Table 2 Presenting symptoms of adult patients with pheochromocytomas, also divided into how they presented.

\begin{tabular}{|c|c|c|c|c|c|c|}
\hline & All $(n=92)$ & $\begin{array}{c}\text { Incidentaloma } \\
\text { presentation }(n=59)\end{array}$ & $\begin{array}{l}\text { Pheo suspicion } \\
\qquad(n=29)\end{array}$ & $\begin{array}{l}P \text { value incidentaloma } \\
\text { vs Pheo suspicion }\end{array}$ & $\begin{array}{l}\text { Screening } \\
\quad(n=4)\end{array}$ & $\begin{array}{c}P \text { value } \\
\text { between all } \\
\text { three groups }\end{array}$ \\
\hline Paroxysmal symptoms $(n)$ & $57(62 \%)$ & $29(49 \%)$ & $26(90 \%)$ & $<0.001$ & $2(50 \%)$ & 0.001 \\
\hline Headaches $(n)$ & $34(37 \%)$ & $17(29 \%)$ & $16(55 \%)$ & 0.020 & $1(25 \%)$ & 0.048 \\
\hline Palpitation (n) & $49(53 \%)$ & $26(44 \%)$ & $22(76 \%)$ & 0.006 & $1(25 \%)$ & 0.010 \\
\hline Sweating $(n)$ & $38(41 \%)$ & $23(39 \%)$ & $15(52 \%)$ & 0.360 & $0(0 \%)$ & 0.120 \\
\hline Pallor $(n)$ & $11(12 \%)$ & $3(5 \%)$ & $7(24 \%)$ & 0.013 & $1(25 \%)$ & 0.025 \\
\hline Anxiety $(n)$ & $42(46 \%)$ & $26(44 \%)$ & $13(45 \%)$ & 0.872 & $3(75 \%)$ & 0.483 \\
\hline Feeling hot/flush $(n)$ & $22(24 \%)$ & $13(22 \%)$ & $9(31 \%)$ & 0.434 & $0(0 \%)$ & 0.336 \\
\hline Nausea $(n)$ & $20(22 \%)$ & $8(14 \%)$ & $12(41 \%)$ & 0.006 & $0(0 \%)$ & 0.007 \\
\hline Weight loss $(n)$ & $15(16 \%)$ & $11(19 \%)$ & $4(14 \%)$ & 0.765 & $0(0 \%)$ & 0.563 \\
\hline Tiredness $(n)$ & $26(28 \%)$ & $18(31 \%)$ & $8(28 \%)$ & 0.973 & $0(0 \%)$ & 0.421 \\
\hline Tremor $(n)$ & $13(14 \%)$ & $4(7 \%)$ & $8(28 \%)$ & 0.017 & $1(25 \%)$ & 0.025 \\
\hline Orthostatic symptoms $(n)$ & $25(27 \%)$ & $11(19 \%)$ & $13(45 \%)$ & 0.019 & $1(25 \%)$ & 0.034 \\
\hline No symptoms at all $(n)$ & $8(9 \%)$ & $7(12 \%)$ & $0(0 \%)$ & 0.090 & $1(25 \%)$ & 0.089 \\
\hline Different symptoms (n) & $3(0-10)$ & $3(0-10)$ & $4(2-8)$ & $<0.001$ & $1(0-6)$ & 0.001 \\
\hline Classic triad (n) & $16(17 \%)$ & $8(14 \%)$ & $8(28 \%)$ & 0.143 & $0(0 \%)$ & 0.170 \\
\hline
\end{tabular}

Pheo, pheochromocytoma. All patients screened due to familial syndrome had a previously known RET mutation (MEN2A). Bold, $P<0.05$. The classic triad with paroxysmal symptoms was defined as headaches, sweating and palpitation.

http://www.endocrineconnections.org

https://doi.org/10.1530/EC-17-0321 (c) 2018 The authors Published by Bioscientifica Ltd

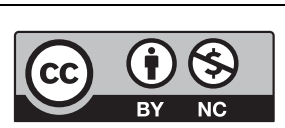

This work is licensed under a Creative Commons Attribution-NonCommercial 4.0 International License. 
Table 3 Correlations in adult patients with pheochromocytomas with different presenting characteristics.

Tumor size vs U-A/P-MNE
Tumor size vs U-NA/P-NMNE
Tumor size vs hormone levels
Tumor size vs P-CGA
Tumor size vs SBP
Tumor size vs DBP
Tumor size vs symptoms
Tumor size vs age
U-A/P-MNE vs SBP
U-A/P-MNE vs DBP
U-A/P-MNE vs symptoms
U-A/P-MNE vs age
U-NA/P-NMNE vs SBP
U-NA/P-NMNE vs DBP
U-NA/P-NMNE vs symptoms
U-NA/P-NMNE vs age
Hormone levels vs SBP
Hormone levels vs DBP
Hormone levels vs symptoms
Hormone levels vs age
Age vs symptoms

\begin{tabular}{ll} 
All $(n=92)$ & Incidentaloma presentation $(n=59)$ \\
\cline { 1 - 1 } NS & NS \\
$R=0.37, P<0.001$ & $R=0.41, P=0.002$ \\
NS & $R=0.30, P=0.027$ \\
$R=0.39, P=0.006$ & NS \\
NS & NS \\
NS & NS \\
NS & NS \\
NS & NS \\
$R=0.39, P<0.001$ & NS \\
$R=0.60, P<0.001$ & NS \\
NS & NS \\
NS & NS \\
$R=0.33, P=0.002$ & NS \\
$R=0.34, P=0.001$ & NS \\
NS & $R=0.43, P<0.001$ \\
NS & NS \\
$R=0.41, P<0.001$ & NS \\
$R=0.36, P<0.001$ & NS \\
NS & $R=0.38, P=0.003$ \\
NS & NS \\
$R=-0.19, P=0.046$ & NS
\end{tabular}

\begin{tabular}{ll} 
Pheo suspicion $(n=29)$ & Screening $(n=4)$ \\
\cline { 1 - 1 } NS & NS \\
$R=0.42, P=0.027$ & NS \\
NS & NS \\
$R=0.78, P=0.005$ & NS \\
NS & NS \\
NS & NS \\
$R=0.33, P=0.049$ & NS \\
NS & NS \\
$R=0.52, P=0.006$ & NS \\
$R=0.37, P=0.043$ & NS \\
NS & NS \\
NS & NS \\
$R=0.36, P=0.042$ & NS \\
$R=0.391, P=0.44$ & NS \\
$R=0.33, P=0.048$ & NS \\
NS & NS \\
$R=0.51, P=0.006$ & NS \\
$R=0.43, P=0.024$ & NS \\
NS & NS \\
NS & NS \\
NS & NS \\
\hline
\end{tabular}

Pheo, pheochromocytoma. All patients screened due to familial syndrome had a previously known RET mutation (MEN2A). U-A/P-MNE, highest U-adrenaline or P-metanephrine level divided by the upper level of normal. U-NA/P-NMNE, highest U-noradrenaline or P-normetanephrine level divided by the upper level of normal. Hormone levels were defined as the highest catecholamine levels divided by the upper level of normal. P-CGA, P-chromogranin A. SBP, systolic blood pressure. DBP, diastolic blood pressure. Symptoms were defined as number of symptoms at presentation. NS, non-significant.

more type 2 diabetes in the suspected pheocromocytoma group. Paroxysmal symptoms were present in almost all with suspected pheochromocytoma while only half of the other groups had these (Table 2). The symptoms that differed significantly between the groups were headaches, palpitations, pallor, nausea, tremor and orthostatic symptoms. The suspected pheocromocytoma group had most different symptoms and the screening group least.

\section{Correlations between different presenting characteristics}

In all patients, there was a positive correlation between tumor size vs noradrenaline/normetanephrine levels and chromogranin A, catecholamine levels vs blood pressure and a negative correlation between age vs number of symptoms (Table 3). In the different subgroups, there were most different correlations in the pheochromocytoma suspicion group and some in the AI presentation group.

\section{Discussion}

This large modern study confirms the wide spectrum of presentations of pheochromocytomas but also that hypertension and typical symptoms may not be present at all. The predominant presentation was serendipitously in the workup of an incidentaloma. Even though the patients with incidentalomas had not sought medical attention for pheochromocytoma-related symptoms, in hindsight, 88\% had symptoms, which could be related to this disorder. Those screened had very few symptoms while those found in the workup of suspected pheochromocytoma had most symptoms. The classic triad, i.e., headaches, sweating and palpitation, was only present in a minority of patients.

Amar and coworkers reported in their study that 15\% presented as an incidentaloma. However, their study spanned from 1975 to 2003 and if only those 48 diagnosed during the last quartile of this period were considered, $25 \%$ presented as an incidentaloma (7). Also other studies, spanning from 1973 to 2011 have found $<10 \%-41 \%$ of patients with pheochromocytoma in the course of imaging for something unrelated $(12,13,14,15)$. Thus, the presentation as an incidentaloma was much higher in our study (64\%); however, we included patients up to 2016 and the increased use of imaging techniques could probably explain the difference. The high proportion of incidentalomas in our study was probably the main reasons why the rate of bilateral tumors was so low. In accordance with this, the rate of bilateral pheochromocytomas 
decreased in the investigation by Amar and coworkers over time (7). Moreover, our study only investigated the initial presentation and a pheochromocytoma may be found in the other adrenal during long-time follow-up increasing the rate of bilateral tumors. It can be assumed that this presentation will continue to increase in the future with even easier access to radiology. Even though a catecholamine-secreting tumor was not suspected in these cases, in hindsight, these were not silent tumors. Around half had paroxysmal symptoms, two-thirds had hypertension, glucose abnormalities were present in almost half and a third had cardiovascular disease. This demonstrates the difficulties in suspecting this potentially lethal condition.

Even though the characteristics in pheochromocytomas presenting as incidentaloma, suspected pheochromocytoma and in screening have been compared previously (12), this is the largest and most detailed study including all the different symptoms so far. We found correlations with different presenting characteristics, even in the subgroups. For example, we demonstrated a relationship between tumor size and hormone level in the entire group, in the incidentaloma and the suspected pheochromocytoma groups, which has previously only been reported once (12). We also found correlations between catecholamine levels and blood pressure in the entire and pheochromocytoma suspicion groups and associations between catecholamine levels and the number of symptoms, however, not that consistent, which have not been reported previously.

Unfortunately, the screening group in the present study consisted of only four individuals; however, the result did not differ much if only the two larger groups were compared. Generally, those suspected of having a pheochromocytoma were males, had higher noradrenaline/normetanephrine levels, higher blood pressure, more general and paroxysmal symptoms and were more affected by type 2 diabetes and cardiovascular disease (the latter two were not significant), while those with a familial syndrome were females (3/4) and had very little symptoms and signs since they were found very early, thanks to regular screening. Those screened had smaller tumors, in accordance with others (12), but this did not reach a significant level in our study. Those with incidentalomas were older than the other groups. It is worth noting that $25 \%$ of those with familial syndrome did not have any symptoms in spite of a catecholaminesecreting tumor being known and symptoms were actively sought after. In the incidentaloma group, no symptoms were found in $12 \%$. Thus, most patients had symptoms but these had not been identified to be related to a pheochromocytoma before the biochemical results came back. In the entire cohort, 9\% did not have any symptoms at all which is similar to others $(7,13)$. Sustained hypertension was present in $63 \%$ of those with an incidentaloma, in $80 \%$ of those suspected of having a pheochromocytoma and in none of those screened. A quarter off all, a third of the incidentaloma group, less than a tenth of the suspected pheochromocytoma group and all in the screening group did not even have paroxysmal hypertension, which seems lower incidence than in some $(7,13)$, but not all publications (14). However, we may have missed some with paroxysmal hypertension. Thus, normal blood pressure cannot exclude a pheochromocytoma. A large proportion, except in the screening group, had had a cardiovascular event before being diagnosed with pheochromocytoma. It could be suspected that the increased catecholamine secretion had contributed to this event in most cases, and one could wonder how many fatal cardiovascular events associated with pheochromocytomas have occurred without being diagnosed (16). Five of our cases presented with a pheochromocytoma crisis with multi-organ failure, which is a life-threating event needing prompt recognition, initial stabilization and sufficient $\alpha$-blockage prior to surgery (15). Laparoscopic transperitoneal adrenalectomy is considered the 'gold standard', at least for tumors $<6 \mathrm{~cm}$, but adrenalectomy by a mininvasive retroperitoneal approach is increasing in popularity (17). Our frequency of $5 \%$ crisis is lower than the $11 \%$ reported from a multicenter German study; however, they included all being admitted to ICU due to a pheochromocytoma-related complication, but only $3 \%$ had, similar to our results, multi-organ failure (7).

Even though most patients did not have a suspicion of a pheochromocytoma initially, after being diagnosed, the frequency of different symptoms in the incidentaloma and suspected pheochromocytoma groups were fairly similar to what others have reported in the last decade (13). Even though the classical triad has been reported to have a specificity and sensitivity of more than $90 \%$ (18), only $17 \%$ had the classic triad in the present study (28\% in those with suspected pheochromocytoma), which is similar to others (14). Thus, nowadays pheochromocytomas do not frequently present with the classic triad.

The inherent limitations of all retrospective studies, in particular that of ascertainment bias, were also present in this study. Even though the study was large comparing to similar single-center studies, the screening group only included four individuals. Moreover, we were not able to

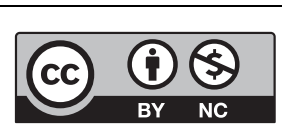

This work is licensed under a Creative Commons Attribution-NonCommercial 4.0 International License. 
standardize the measurements of hormonal and genetic tests due to the retrospective nature of the study.

In conclusion, the clinical presentation of pheochromocytomas can be anything from asymptomatic to a dramatic life-threatening event. This rare condition is important to bear in mind in the workup of patients with incidentalomas, which nowadays were the most common presentation of pheochromocytomas due to the better availability and accessibility of imaging procedures. In hindsight, most of these were not asymptomatic, but due to the diffuse symptoms, catecholamine-secreting tumors were not considered. A normal blood pressure did not exclude a pheochromocytoma. Clinicians need to be aware of the clinical presentation of pheochromocytomas today since their early identification can be life-saving.

\section{Declaration of interest}

The authors declare that there is no conflict of interest that could be perceived as prejudicing the impartiality of the research reported.

\section{Funding}

This was an academic investigation with funding from the Magnus Bergvall Foundation. This study was supported by Karolinska Institutet and the Stockholm County Council.

\section{References}

1 Lenders JW, Duh QY, Eisenhofer G, Gimenez-Roqueplo AP, Grebe SK, Murad MH, Naruse M, Pacak K, Young WF Jr \& Endocrine S. Pheochromocytoma and paraganglioma: an endocrine society clinical practice guideline. Journal of Clinical Endocrinology and Metabolism 201499 1915-1942.

2 Yeomans H, Calissendorff J, Volpe C, Falhammar H \& Mannheimer B. Limited value of long-term biochemical follow-up in patients with adrenal incidentalomas-a retrospective cohort study. BMC Endocrine Disorders 201515 6. (https://doi.org/10.1186/s12902-015-0001-x)

3 Patrova J, Jarocka I, Wahrenberg H \& Falhammar H. Clinical outcomes in adrenal incidentaloma: experience from one center. Endocrine Practice 201521 870-877. (https://doi.org/10.4158/ EP15618.OR)

4 Mantero F, Terzolo M, Arnaldi G, Osella G, Masini AM, Ali A, Giovagnetti M, Opocher G \& Angeli A. A survey on adrenal incidentaloma in Italy. Study Group on Adrenal Tumors of the Italian Society of Endocrinology. Journal of Clinical Endocrinology and Metabolism 200085 637-644.

5 Riester A, Weismann D, Quinkler M, Lichtenauer UD, Sommerey S, Halbritter R, Penning R, Spitzweg C, Schopohl J, Beuschlein F, et al. Life-threatening events in patients with pheochromocytoma. European Journal of Endocrinology 2015173 757-764. (https://doi. org/10.1530/EJE-15-0483)

6 Khorram-Manesh A, Ahlman H, Nilsson O, Oden A \& Jansson S. Mortality associated with pheochromocytoma in a large Swedish cohort. European Journal of Surgical Oncology 200430 556-559. (https://doi.org/10.1016/j.ejso.2004.03.006)

7 Amar L, Servais A, Gimenez-Roqueplo AP, Zinzindohoue F, Chatellier G \& Plouin PF. Year of diagnosis, features at presentation, and risk of recurrence in patients with pheochromocytoma or secreting paraganglioma. Journal of Clinical Endocrinology and Metabolism 200590 2110-2116. (https://doi.org/10.1210/jc.20041398)

8 Patrova J, Kjellman M, Wahrenberg H \& Falhammar H. Increased mortality in patients with adrenal incidentalomas and autonomous cortisol secretion: a 13-year retrospective study from one center. Endocrine 201758 267-275. (https://doi.org/10.1007/s12020-0171400-8)

9 Falhammar H, Frisen L, Hirschberg AL, Norrby C, Almqvist C, Nordenskjold A \& Nordenstrom A. Increased cardiovascular and metabolic morbidity in patients with 21-hydroxylase deficiency: a Swedish population-based national cohort study. Journal of Clinical Endocrinology and Metabolism 2015100 3520-3528. (https://doi. org/10.1210/JC.2015-2093)

10 Falhammar H, Calissendorff J \& Hoybye C. Frequency of Cushing's syndrome due to ACTH-secreting adrenal medullary lesions: a retrospective study over 10 years from a single center. Endocrine 2017 55 296-302. (https://doi.org/10.1007/s12020-016-1127-y)

11 Calissendorff J, Calissendorff F \& Falhammar H. Adrenocortical cancer: mortality, hormone secretion, proliferation and urine steroids - experience from a single centre spanning three decades. $B M C$ Endocrine Disorders 201616 15. (https://doi.org/10.1186/s12902-0160095-9)

12 Guerrero MA, Schreinemakers JM, Vriens MR, Suh I, Hwang J, Shen WT, Gosnell J, Clark OH \& Duh QY. Clinical spectrum of pheochromocytoma. Journal of the American College of Surgeons 2009 209 727-732. (https://doi.org/10.1016/j.jamcollsurg.2009.09.022)

13 Kopetschke R, Slisko M, Kilisli A, Tuschy U, Wallaschofski H, Fassnacht M, Ventz M, Beuschlein F, Reincke M, Reisch N, et al. Frequent incidental discovery of phaeochromocytoma: data from a German cohort of 201 phaeochromocytoma. European Journal of Endocrinology 2009161 355-361. (https://doi.org/10.1530/EJE-09-0384)

14 Baguet JP, Hammer L, Mazzuco TL, Chabre O, Mallion JM, Sturm N \& Chaffanjon P. Circumstances of discovery of phaeochromocytoma: a retrospective study of 41 consecutive patients. European Journal of Endocrinology 2004150 681-686. (https://doi.org/10.1530/ eje.0.1500681)

15 Scholten A, Cisco RM, Vriens MR, Cohen JK, Mitmaker EJ, Liu C, Tyrrell JB, Shen WT \& Duh QY. Pheochromocytoma crisis is not a surgical emergency. Journal of Clinical Endocrinology and Metabolism 201398 581-591. (https://doi.org/10.1210/jc.2012-3020)

16 Gu YW, Poste J, Kunal M, Schwarcz M \& Weiss I. Cardiovascular manifestations of pheochromocytoma. Cardiology in Review 201725 215-222. (https://doi.org/10.1097/CRD.0000000000000141)

17 Conzo G, Tartaglia E, Gambardella C, Esposito D, Sciascia V, Mauriello C, Nunziata A, Siciliano G, Izzo G, Cavallo F, et al. Minimally invasive approach for adrenal lesions: systematic review of laparoscopic versus retroperitoneoscopic adrenalectomy and assessment of risk factors for complications. International Journal of Surgery 201628 (Supplement 1) S118-S123. (https://doi. org/10.1016/j.ijsu.2015.12.042)

18 Plouin PF, Degoulet P, Tugaye A, Ducrocq MB \& Menard J. Screening for phaeochromocytoma: in which hypertensive patients? A semiological study of 2585 patients, including 11 with phaeochromocytoma (author's transl). La Nouvelle Presse Medicale $198110869-872$.

Received in final form 29 November 2017

Accepted 7 December 2017

Accepted Preprint published online 7 December 2017 http://www.endocrineconnections.org https://doi.org/10.1530/EC-17-0321 (c) 2018 The authors Published by Bioscientifica Ltd

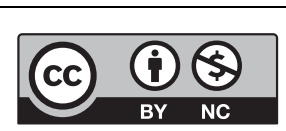

This work is licensed under a Creative Commons Attribution-NonCommercial 4.0 International License. 